\title{
Validation of an asthma symptom diary for interventional studies
}

Nancy C Santanello, Glenn Davies, Stanley P Galant, Andrew Pedinoff, Richard Sveum, James Seltzer, Beth C Seidenberg, Barbara A Knorr

\begin{abstract}
Objective-The Pediatric Asthma Diary was developed and validated to assess efficacy of interventions in children with asthma.

Design, patients, and setting-Diary validation was performed in a three week, prospective study of 106 children aged 6-14 years with asthma. Children were classified at baseline as either stable (requiring no additional asthma treatment) or new onset/worse (requiring either addition of or increase in antiinflammatory treatment).

Results-A daytime symptom scale and "day without asthma" were defined from diary questions. Both measures demonstrated significant validity and responsiveness to anti-inflammatory treatment. The stable group experienced a higher percentage of days without asthma during week 1 compared with the new onset/worse group $(39.6 \% v 11.6 \%$, respectively). The new onset/worse patients experienced significant improvement in days without asthma $(24.5 \%)$ compared with stable patients $(6.4 \%)$.
\end{abstract}

Conclusions-The Pediatric Asthma Diary daytime symptom scale and day without asthma are acceptable measures for use in asthma intervention studies of children aged $6-14$ years.

(Arch Dis Child 1999;80:414-420)

Keywords: asthma; outcomes research; reliability and validity; questionnaire; Pediatric Asthma Diary

As an end point in clinical trials, pulmonary function tests provide an objective assessment of airway obstruction, but do not assess how the patient with asthma feels. Asthma related outcome measures that query patient perceptions are recognised as important tools to help provide a more complete assessment of the effectiveness of asthma treatment in clinical trials in adults and children. ${ }^{1}$

Selection of asthma related outcome measures should be based on information that demonstrates acceptable measurement characteristics of the measure; the instrument should be reliable and valid. For interventional studies, outcome measures also need to provide a valid measure of change-that is, the outcome measure should be responsive to clinically important changes in health status. ${ }^{1-4}$ The literature provides a number of asthma related outcome measures for children with asthma, or their parents, that are partially or wholly validated with respect to these criteria. These measures include assessment of such outcomes as asthma specific quality of life, asthma self efficacy, asthma self management, and asthma symptom questionnaires. ${ }^{5-11}$ Some of these questionnaires were developed and validated to be used as surveys, rather than as measures of change in asthma as a result of treatment, ${ }^{10-12}$ and therefore may be inappropriate for use in clinical trials.

We attempted to find a validated asthma symptom daily diary scale to use as an outcome measure of asthma treatment in a clinical trial of 6 to 14 year olds. We were interested in obtaining the child's perspective on their asthma symptoms and how their symptoms limited them, rather than a parental report of the child's symptoms (proxy measure). A literature search and information acquired through the Freedom of Information $\mathrm{Act}^{13}$ revealed that no fully validated daily diary scale to assess change in asthma symptoms and symptom effects in children and adolescents was available. ${ }^{13-17}$ Therefore, in our study we aimed to develop and validate an asthma symptom diary scale completed by children and adolescents aged 6-14 years (with parental assistance) for use in paediatric clinical trials of asthma treatment.

\section{Methods}

DEVELOPMENT OF A PAEDIATRIC ASTHMA

SYMPTOM DIARY SCALE

Questions for a paediatric asthma symptom diary were developed from a previously validated adult symptom diary scale, ${ }^{18}$ unvalidated paediatric diaries in the literature, ${ }^{14-17}$ and the childhood asthma management programme diary card. ${ }^{13}$ Interviews with children were used to construct appropriate wording for children. The diary record included a daytime symptom scale consisting of three questions and a question regarding awakening with asthma (Appendix). In addition, the diary included questions on school loss, and the need for urgent medical care (urgent physician or emergency department visits or hospitalisations), or the need for oral corticosteroids. "As needed" puffs of $\beta$ agonist inhaler and peak expiratory flow (PEF) were recorded twice daily on the diary card. The diary record was pilot tested, revised, and re-pilot tested in four separate and sequential groups of children with asthma aged 6-14 years and their parents/guardians. Each group contained six to 10 children and their parents/guardians. The pilot test examined the clarity of the diary format, understanding of the questions, and response options, and ability to 
complete the diary. ${ }^{19} 20$ The diary questions were pilot tested in paper and pen format and in an electronic entry format.

\section{VALIDATION STUDY DESIGN}

A study was designed to examine the measurement characteristics of the newly developed and pilot tested Pediatric Asthma Diary (Copyright 1995 Merck \& Co Inc) scale. The validation study was a three week, single period, open, prospective study of 6-14 year old children and adolescents with mild to moderate asthma. Approximately 100 children and adolescents with asthma were to be recruited for the study at eight clinical sites, with approximately equal numbers of patients in two age categories (6-8 year olds and 9-14 year olds). A baseline visit (visit 1) determined the eligibility of the children and adolescents. Children and adolescents who had a history of asthma in the past were eligible if they had typical symptoms of asthma-including but not limited to cough, wheezing, and shortness of breath-and documented evidence in the last six months of one or more of the following within the preceding year: an abnormal forced expiratory volume in one second $\left(\mathrm{FEV}_{1}\right.$; $\leqslant 90 \%$ of predicted); reversibility of airway obstruction within 30 minutes following the administration of $\beta$ agonist ( $\geqslant 15 \%$ increase in $\mathrm{FEV}_{1}$ ); positive exercise challenge test (decline in $\mathrm{FEV}_{1} \geqslant 10 \%$ ); abnormal methacholine or histamine challenge test (provocative concentration causing a $20 \%$ fall in $\mathrm{FEV}_{1}\left(\mathrm{PC}_{20} \mathrm{FEV}_{1}\right)$ $\leqslant 90 \%$ predicted). Those children and adolescents who had new onset of asthma symptoms were eligible if they had typical symptoms of asthma as described above and an abnormal $\mathrm{FEV}_{1} \leqslant 90 \%$ of that predicted at visit 1 .

Within each age category, two separate groups of children were to be enrolled: (1) a group of children judged by the investigator to have stable asthma at baseline (stable group); and (2) a group of children judged by the investigator to have either new onset of asthma or worsening asthma at baseline (new onset/worse group). Children in the stable group received no change in their current anti-inflammatory asthma treatment during the study, whereas children in the new onset/worse group required either initiation of anti-inflammatory treatment or an increase in their present antiinflammatory treatment at baseline, which was maintained for the study duration. Both groups continued to use their usual $\beta$ agonist metered dose inhaler on an "as needed" basis.

Follow up visits occurred weekly for three weeks after entry (visits 2, 3, and 4). Spirometry measurements were obtained in the clinic at baseline (visit 1), after one week of treatment (visit 2), and at the end of the three week study (visit 4). Parents were asked to withhold use of $\beta$ agonist inhalers for at least four hours before the clinic visits. A validated asthma specific paediatric quality of life questionnaire consisting of 23 items in three domains (symptoms, activity limitation, and emotional function) was completed in the clinic by the 9-14 year old children and adolescents at baseline and at the end of the three week study. ${ }^{5}$

The diary questions were administered on a hand held, electronic diary record. Back up paper diary records were available in case of an electronic diary failure. The daytime asthma diary was completed each evening before bed by the children aged 9-14 years, with the supervision of their parent/guardian. For the 6-8 year olds, the parents read the questions and responses on the diary verbatim at bedtime to their child and then entered the child's answer. The daytime diary record consisted of a series of questions inquiring about asthma symptoms; loss of time from school as a result of asthma; need for an unscheduled visit to an emergency department or physician, hospitalisation, or oral prednisone as a result of asthma; number of puffs of $\beta$ agonist inhaler used since waking up; the best of three PEF measurements before going to sleep and whether or not the PEF was performed within four hours of the last $\beta$ agonist inhaler use.

The night-time asthma symptom diary record was completed each morning on waking up for the day. The night-time record asked about awakenings with asthma symptoms, number of puffs of $\beta$ agonist inhaler used since going to sleep, and the best of three PEF measurements on awakening in the morning. Parents were asked to withhold $\beta$ agonist inhaler for at least four hours before measuring PEF. As with the daytime diary questions, children 9-14 years of age recorded their responses on the night-time diary with the supervision of their parents/guardians, and the parents of children 6-8 years of age read the questions and responses to their child and recorded the child's answer.

DIARY SCALES SCORING AND ANALYTICAL METHODS

The daytime asthma symptom scale consisted of three questions scored on a 6 point scale from 0 (symptoms none of the time, no bother and effect on daily activities at any time) to 5 (symptoms all of the time, greatest bother possible and effect on activities all of the time). The nocturnal diary included a single question scored on a 4 point scale from 0 (no awakenings) to 3 (awake all night).

The daytime asthma symptom questions and the awakening question were examined for test/retest reliability, discriminant validity, longitudinal construct validity, and responsiveness. Test/retest reliability was assessed with the intraclass correlation coefficients (ICC) using data for all 106 patients from study week 2 (visit 3) and study week 3 (visit 4) diary data. This period was hypothesised to be a period of time when the patients' asthma would be stable. $^{21}$ An ICC of 0.75 and above is considered acceptable in a research instrument. ${ }^{22}$

Longitudinal construct validity was evaluated with Spearman's correlation coefficients to determine the relation between changes in the diary questions and other clinical asthma measures $\left(\mathrm{FEV}_{1}, \mathrm{PEF}\right.$, and puffs of $\beta$ agonist used). Changes in the diary scale questions 
Table 1 Baseline characteristics for patients by baseline asthma status

\begin{tabular}{|c|c|c|c|}
\hline & Stable $(n=53)$ & New onset/worse $(n=53)$ & Total $(n=106)$ \\
\hline \multicolumn{4}{|l|}{ Age (years) } \\
\hline Mean (SD) & $9.2(2.3)$ & $9.4(2.4)$ & $9.3(2.4)$ \\
\hline Range & 6 to 14 & 6 to 14 & 6 to 14 \\
\hline \multicolumn{4}{|l|}{ Sex $(\%)$} \\
\hline Female & $18(34)$ & $16(30)$ & $34(32)$ \\
\hline Male & $25(66)$ & $37(70)$ & $62(68)$ \\
\hline \multicolumn{4}{|l|}{ Race $(\%)$} \\
\hline White & $49(92)$ & $49(92)$ & $98(92)$ \\
\hline Other (black, Asian, etc) & $4(8)$ & $4(8)$ & $4(8)$ \\
\hline \multicolumn{4}{|l|}{ Visit 1} \\
\hline \multicolumn{4}{|l|}{$\%$ Predicted $\mathrm{FEV}_{1}$} \\
\hline Mean (SD) & $83.7(10.9)$ & $77.8(18.9)^{\star}$ & $80.7(15.7)$ \\
\hline Range & $63-131$ & $27-117$ & $27-131$ \\
\hline \multicolumn{4}{|l|}{ Visit 2} \\
\hline \multicolumn{4}{|l|}{$\%$ Predicted $\mathrm{FEV}_{1}$} \\
\hline Mean (SD) & $82.5(12.6)$ & $84.9(18.2)$ & $83.7(15.6)$ \\
\hline Range & $39-103$ & $45-125$ & $39-125$ \\
\hline \multicolumn{4}{|l|}{ Week 1} \\
\hline \multicolumn{4}{|c|}{ Daytime daily $\beta$ agonist (puffs/day) } \\
\hline Mean (SD) & $1.2(1.7)$ & $3.1(2.3) \dagger$ & $2.2(2.2)$ \\
\hline Range & 0.0 to 7.7 & 0.0 to 8.4 & $0.0-8.4$ \\
\hline \multicolumn{4}{|c|}{ Overnight $\beta$ agonist (puffs/night) } \\
\hline Mean (SD) & $0.3(0.6)$ & $0.5(0.9)^{\star}$ & $0.4(0.8)$ \\
\hline Range & $0.0-3.0$ & $0.0-4.0$ & $0.0-4.0$ \\
\hline \multicolumn{4}{|l|}{ PEF in morning $(1 / \mathrm{min})$} \\
\hline Mean (SD) & $269.5(80.7)$ & $258.8(81.0)$ & $264.1(80.8)$ \\
\hline Range & $126.7-473.3$ & $80.2-455.0$ & $80.2-473.3$ \\
\hline \multicolumn{4}{|l|}{$\mathrm{PEF}$ in evening $(1 / \mathrm{min})$} \\
\hline Mean (SD) & $280.0(80.0)$ & $276.3(75.4)$ & $278.2(77.4)$ \\
\hline Range & $153.0-477.0$ & $101.8-447.0$ & $101.8-477.1$ \\
\hline
\end{tabular}

$\star_{\mathrm{p}}<0.10 ; \mathrm{tp}<0.0001$ for difference between new onset/worse group and stable group.

were also related to changes in the three domains of a previously validated asthma specific paediatric quality of life questionnaire to determine how the diary questions relate to this asthma outcome measure. The three daytime symptom questions were evaluated for internal consistency with Cronbach's alpha. Internal consistency estimates the extent to which each item of a questionnaire is measuring the same construct. ${ }^{23}$ Good internal consistency is defined as an alpha coefficient $>0.70$ and $<0.95$. $^{24}$

Week 1 average scores were used to assess the ability of the diary questions to discriminate between patients in the stable group and those in the new onset/worse group (discriminant validity). Because the data were not normally distributed, we applied nonparametric statistics methodology, and compared the week 1 scores for the two asthma groups with Wilcoxon's rank sum test. ${ }^{25}$

We used changes in the average asthma diary scores from week 1 to week 3 to evaluate the ability of the diary questions to assess changes in the patients' asthma over the course of our study. Again, because the data were not normally distributed, we used Wilcoxon signed rank test to evaluate the within group change scores for each outcome variable and Wilcoxon rank sum test to compare responses across asthma groups. $^{25}$

In addition to the daytime and night-time diary questions a composite summary variable was created to determine a child's percentage of days without asthma. A day without asthma was defined as a day that met all of the following criteria: no $\beta$ agonist use (either daytime or night-time), no daytime asthma symptoms (symptom score, 0 ), no night-time awakenings, no unscheduled visits to a physician or an emergency department or admission to a hospital for asthma, and no oral steroid use.
Each child's percentage of days without asthma was calculated for each week in the study. The percentage of days without asthma was compared between the stable and new onset/worse groups for week 1 (discriminant validity), and the change from week 1 to week 3 in the average days without asthma each week was compared between groups (responsiveness of the days without asthma measure to change in asthma treatment).

The number of school days missed and the number of asthma attacks are reported to describe differences between the study children with stable asthma and new onset/worse asthma. The number of children who missed one or more school days and the total number of days missed divided by the total number of school days are reported by study week and for the total study period. Asthma attacks were defined in the diary record as a visit to a doctor, emergency department, or hospital for asthma (other than a scheduled visit to a doctor), or treatment with oral steroids during the previous 24 hours. Response options were "yes" = 1 or "no" $=0$. The number of children who had one or more attack days, and the total number of attack days divided by the total number of study days are reported by study week and for the total study period. The stable and new onset/worse asthma populations were compared at week 1 with respect to the difference in the proportion of children who missed one or more school days (that is, the difference between two binomial proportions), and with respect to the proportion of children who had at least one attack day.

\section{Results}

One hundred and six patients, aged $6-14$ years, were enrolled across the eight clinical sites. Fifty three children were classified into the stable asthma group (requiring no change in asthma treatment) and 53 children into the new onset or worsening asthma group (requiring either initiation or increase in antiinflammatory asthma treatment). Table 1 provides demographic data, visit 1 per cent predicted $\mathrm{FEV}_{1}$, week 1 diary data for PEF, and puffs of $\beta$ agonist inhaler used for children in the stable asthma group and new onset/worse asthma group. As planned, the number of children in each age category was comparable (54 $(51 \%)$ of the children were $6-8$ years of age and $52(49 \%)$ were $9-14$ years of age).

The baseline data show that the stable and new onset/worse groups were similar in mean age, sex, and race. As expected, the mean per cent predicted $\mathrm{FEV}_{1}$ at visit 1 was less $(p<0.053)$ and the use of $\beta$ agonist during the day (daytime $\beta$ agonist use) for week 1 was significantly greater $(p<0.0001)$ for the new onset/worse patients than for the stable patients. Also as expected, morning and evening PEF measures were lower, but the differences were marginal, and the use of overnight $\beta$ agonist inhalers was slightly greater in the new onset/worse group.

Excellent internal consistency of the three asthma symptom daytime questions was demonstrated by a Cronbach's alpha of 0.94 , 
Table 2 Assessment of discriminant validity: scores for week 1 for daytime and awakening symptom diary records

Stable patients $(n=53) \quad$ New onset/worse $(n=53) \quad p$ Value

\begin{tabular}{|c|c|c|c|}
\hline \multicolumn{4}{|l|}{ Daytime diary } \\
\hline \multicolumn{4}{|l|}{ Trouble breathing } \\
\hline Mean (SD) & $0.68(0.78)$ & $0.93(0.62)$ & \multirow[t]{2}{*}{0.008} \\
\hline Median (range) & $0.3(0-4)$ & $0.86(0-2.4)$ & \\
\hline \multicolumn{4}{|l|}{ Asthma bother } \\
\hline Mean (SD) & $0.58(0.61)$ & $0.95(0.60)$ & \multirow[t]{2}{*}{$<0.001$} \\
\hline Median (range) & $0.33(0-2.4)$ & $0.86(0-2.1)$ & \\
\hline \multicolumn{4}{|l|}{ Activity limitation } \\
\hline Mean (SD) & $0.41(0.70)$ & $0.71(0.64)$ & \multirow[t]{2}{*}{0.001} \\
\hline Median (range) & $0.14(0-4.1)$ & $0.57(0-2.9)$ & \\
\hline \multicolumn{4}{|c|}{ Combined daytime symptom score } \\
\hline Mean (SD) & $0.56(0.67)$ & $0.86(0.57)$ & \multirow{2}{*}{0.001} \\
\hline Median (range) & $0.29(0-3.4)$ & $0.86(0-2.2)$ & \\
\hline \multicolumn{4}{|l|}{ Night time diary } \\
\hline \multicolumn{4}{|l|}{ Awakening score } \\
\hline Mean (SD) & $0.11(0.20)$ & $0.17(0.23)$ & \multirow[t]{2}{*}{0.103} \\
\hline Median (range) & $0.00(0-1)$ & $0.00(0-1)$ & \\
\hline \multicolumn{4}{|c|}{ Days without asthma (\%) } \\
\hline Mean (SD) & $39.6(35.5)$ & $11.6(21.3)$ & \multirow[t]{2}{*}{$<0.001$} \\
\hline Median (range) & $28.5(0-100)$ & $0.00(0-100)$ & \\
\hline
\end{tabular}

p values are for stable $v$ new onset/worse patients.

${ }^{\star}$ Only $48(45 \%)$ of 106 patients experienced awakenings with asthma in the first week.

which demonstrates that the three daytime asthma symptom questions and the activity question can be combined into one daytime asthma symptom/activity scale. For each study week, the mean scores of the daytime asthma symptom questions and the awakening question for both the new onset/worse and stable groups were less than 1 (out of a possible 6 point scale for the three daytime symptoms (range, 0-5) and a 4 point scale for the night-time awakenings question (range, $0-3)$ ). Only 48 of the children ( $45 \%$ ) had at least one nocturnal awakening as a result of asthma during the first week (20 patients in the stable group (38\%) and 28 patients in the new onset/ worse group (53\%)).

Table 2 gives the mean (SD) scores, median, and range of scores for the three daytime diary asthma symptom questions, and the night-time diary awakening as a result of asthma question for study week 1 . The three average daytime asthma symptom question scores and the total daytime symptoms/activity scale scores were significantly worse (greater) in the new onset/ worse group compared with the stable group for the first week of our study, demonstrating good discriminant validity of the questions and the total symptom/activity scale. There was no significant difference in the mean score for the asthma awakening question between the two groups.
Table 2 also gives the differences between the stable and new onset/worse groups for the days without asthma during week 1 . There were significant differences between groups, with an average of $39.6 \%$ of days being a day without asthma in the stable group compared with $11.6 \%$ of days in the new onset/worse group $(\mathrm{p}<0.001)$.

The ICC values measuring test/retest reliability for the symptom questions on all patient data combined from visit 3 to visit 4 were acceptable for the frequency and bother of daytime asthma symptoms questions. The ICC values for the daytime questions were: 0.76 ( $95 \%$ CI, 0.67 to 0.83 ) for the trouble breathing question; 0.77 (95\% CI, 0.68 to 0.84 ) for asthma bother question; and $0.72(95 \% \mathrm{CI}$, 0.61 to 0.80 ) for the activity limitation question. The combined asthma symptom scale had an ICC value of 0.77 (95\% CI, 0.68 to 0.84 ). The night-time awakening question did not perform as well on test/retest reliability as the three daytime symptom questions or the combined scale (ICC $=0.56 ; 95 \%$ CI, 0.41 to $0.68)$.

Table 3 shows the Spearman correlation coefficients for longitudinal construct validity. Changes from week 1 to week 3 for the daytime symptom and activity questions correlated moderately with changes in morning and evening PEF and in morning and evening puffs of $\beta$ agonist inhaler used, but not with changes in per cent predicted $\mathrm{FEV}_{1}$ over the same period. The change in the night-time awakening score was correlated best with the change in puffs of $\beta$ agonist recorded in the morning to reflect use overnight $(0.37)$. The change in the combined daytime symptoms scale and the composite measure percentage of days without asthma were both moderately to highly correlated with all diary measures (symptoms, night-time awakenings, morning and evening PEF, and morning and evening of $\beta$ agonist inhaler used), but not with per cent predicted $\mathrm{FEV}_{1}$

The changes from baseline in the three diary symptom questions were significantly related to changes from baseline in all three domains of the asthma specific paediatric quality of life questionnaire (symptoms, activity limitation, and emotional function domains). Coefficients ranged from -0.32 to -0.58 .

Table 4 shows the change in average scores from week 1 to week 3 to assess responsiveness

Table 3 Longitudinal construct validity (Spearman's correlation coefficients) change from week 1 to week 3

\begin{tabular}{|c|c|c|c|c|c|c|c|c|c|c|}
\hline \multirow[b]{2}{*}{ Change in } & \multicolumn{10}{|l|}{ Change in } \\
\hline & $\begin{array}{l}\text { \% days without } \\
\text { asthma }\end{array}$ & $\begin{array}{l}\text { \% predicted } \\
F E V_{1}\end{array}$ & $\begin{array}{l}\text { Morning } \\
P E F\end{array}$ & $\begin{array}{l}\text { Evening } \\
P E F\end{array}$ & $\begin{array}{l}\text { Morning } \\
\text { puffs/day }\end{array}$ & $\begin{array}{l}\text { Evening } \\
\text { puffs/day }\end{array}$ & $\begin{array}{l}\text { Trouble } \\
\text { breathing }\end{array}$ & $\begin{array}{l}\text { Asthma } \\
\text { bother }\end{array}$ & $\begin{array}{l}\text { Activity } \\
\text { limitation }\end{array}$ & Awakening \\
\hline$\%$ predicted $\mathrm{FEV}_{1}$ & 0.04 & & & & & & & & & \\
\hline Morning PEF & $0.39^{\star}$ & 0.11 & & & & & & & & \\
\hline Evening PEF & $0.21^{\star}$ & 0.15 & $0.72^{\star}$ & & & & & & & \\
\hline Morning puffs/day & $-0.21^{\star}$ & -0.05 & -0.14 & $-0.29^{\star}$ & & & & & & \\
\hline Evening puffs/day & $-0.51^{\star}$ & -0.06 & $-0.40^{\star}$ & $0.31^{\star}$ & $0.20^{\star}$ & & & & & \\
\hline Trouble breathing & $-0.55^{\star}$ & -0.08 & $-0.38^{\star}$ & $-0.43^{\star}$ & $0.31^{\star}$ & $0.36 \star$ & & & & \\
\hline Asthma bother & $-0.57^{\star}$ & -0.11 & $-0.41^{\star}$ & $-0.48^{\star}$ & $0.30^{\star}$ & $0.43^{\star}$ & $0.89^{\star}$ & & & \\
\hline Activity limitation & $-0.49^{\star}$ & -0.12 & $-0.29^{\star}$ & $-0.30^{\star}$ & $0.26^{\star}$ & $0.41^{\star}$ & $0.75^{\star}$ & $0.73^{\star}$ & & \\
\hline Awakening & $-0.34^{\star}$ & -0.03 & $-0.19^{\star}$ & $-0.19^{\star}$ & $0.37^{\star}$ & 0.10 & $0.46^{\star}$ & $0.40^{\star}$ & $0.36^{\star}$ & \\
\hline Combined daytime scale score & $-0.61^{\star}$ & -0.11 & $-0.40^{\star}$ & $-0.44^{\star}$ & $0.31^{\star}$ & $0.41^{\star}$ & $0.92^{\star}$ & $0.93^{\star}$ & $0.88^{\star}$ & $0.46^{\star}$ \\
\hline
\end{tabular}

As the symptom score improved (decreased) the $\mathrm{FEV}_{1}$ and PEF both improved (increased).

${ }^{\star} \mathrm{p}<0.05$. 
Table 4 Assessment of responsiveness: changes in average scores for week 1 to week 3 for daytime and awakening symptom diary records

\begin{tabular}{|c|c|c|c|}
\hline & Stable patients $(n=53)$ & New onset/worse $(n=52)$ & $p$ Value \\
\hline \multicolumn{4}{|l|}{ Daytime diary } \\
\hline \multicolumn{4}{|l|}{ Trouble breathing } \\
\hline Mean (SD) & $-0.15(0.64)$ & $-0.15(0.85)$ & \multirow[t]{2}{*}{0.177} \\
\hline Median (range) & $-0.05(-3.33$ to 1.29$)$ & $-0.29(-1.86$ to 2.57$)$ & \\
\hline \multicolumn{4}{|l|}{ Asthma bother } \\
\hline Mean (SD) & $-0.04(0.56)$ & $-0.23(0.80)$ & \multirow[t]{2}{*}{0.009} \\
\hline Median (range) & $0.00(-1.67$ to 1.57$)$ & $-0.29(-2$ to 2.57$)$ & \\
\hline \multicolumn{4}{|l|}{ Activity limitation } \\
\hline Mean (SD) & $-0.05(0.77)$ & $-0.04(0.85)$ & \multirow[t]{2}{*}{0.272} \\
\hline Median (range) & $0.00(-4.14$ to 1.86$)$ & $0.00(-2.00$ to 3.00$)$ & \\
\hline \multicolumn{4}{|c|}{ Combined daytime symptom score } \\
\hline Mean (SD) & $-0.25(1.87)$ & $-0.42(2.39)$ & \multirow[t]{2}{*}{0.037} \\
\hline Median (range) & $0.00(-9.14$ to 4.71$)$ & $-0.71(-4.37$ to 8.14$)$ & \\
\hline \multicolumn{4}{|l|}{ Night time diary } \\
\hline \multicolumn{4}{|l|}{ Awakening score ${ }^{\star}$} \\
\hline Mean (SD) & $0.02(0.27)$ & $-0.02(0.34)$ & \multirow[t]{2}{*}{0.198} \\
\hline Median (range) & $0.00(-0.86$ to 0.83$)$ & $0.00(-0.83$ to -1.27$)$ & \\
\hline \multicolumn{4}{|c|}{ Days without asthma (\%) } \\
\hline Mean (SD) & $6.4(26.9)$ & $24.5(33.6)$ & \multirow[t]{2}{*}{0.004} \\
\hline Median (range) & $0.00(-43.0$ to 100$)$ & $14.3(-28.6$ to 100$)$ & \\
\hline
\end{tabular}

$\mathrm{p}$ values are stable $v$ new onset/worse patients.

${ }^{\star}$ Only $48(45 \%)$ of 106 patients experienced awakenings with asthma in the first week.

of the diary daytime symptom questions, the night-time awakening score, and the percentage of days without asthma. Of the four symptom and awakening questions, only the question for bother of asthma symptoms showed a significant difference in change score between the groups. Children in the stable group experienced on average only a $6.4 \%$ increase in their percentage of days without asthma from study week 1 to week 3 $(p>0.10)$, whereas children in the unstable group experienced a $24.5 \%$ increase $(\mathrm{p}<0.001)$. The responsiveness over the three weeks in the new onset/worse group was significantly greater for percentage of days without asthma $(\mathrm{p}=0.004)$ compared with the children in the stable group (table 4 ; fig 1 ).

Table 5 provides the frequency of school loss reported in the stable and new onset/ worse groups of children. The new onset/ worse group reported more school loss days $(\mathrm{p}=0.0003)$. An analysis of asthma attack days was also conducted. There were a significantly greater number of asthma attack days in the new onset/worse group ( $p<0.0001)$ than the stable group in the first week of the study. The differences between groups for study weeks 2 and 3 decreased for both school loss days and asthma attack days after treatment intervention.

\section{Discussion}

A paediatric asthma symptom diary record (Pediatric Asthma Diary) was developed as a tool to measure change in asthma for use in

Table 5 Missed school days by stable and new onset/worse groups

\begin{tabular}{|c|c|c|c|c|}
\hline & \multicolumn{2}{|c|}{$\begin{array}{l}\text { Number of children missing one } \\
\text { or more school days }\end{array}$} & \multicolumn{2}{|c|}{$\begin{array}{l}\text { Number of school days } \\
\text { missed/number of school days (\%) }\end{array}$} \\
\hline & $\begin{array}{l}\text { Stable group } \\
(n=53)\end{array}$ & $\begin{array}{l}\text { New onset/worse } \\
\text { group }(n=53)\end{array}$ & $\begin{array}{l}\text { Stable group } \\
(n=53)\end{array}$ & $\begin{array}{l}\text { New onset/worse } \\
\text { group }(n=53)\end{array}$ \\
\hline Week 1 & 5 & $15^{\star}$ & $5 / 239(2.1)$ & $27 / 268(10.1)$ \\
\hline Week 2 & 5 & 7 & $6 / 257(2.3)$ & $13 / 274(4.7)$ \\
\hline Week 3 & 4 & 7 & $4 / 306(1.3)$ & $10 / 334(3.0)$ \\
\hline $\begin{array}{l}\text { Total school days missed } \\
\quad(\text { weeks } 1,2 \text {, and } 3 \text { ) }\end{array}$ & 12 & 23 & $23 / 809(2.2)$ & $50 / 876(5.7)$ \\
\hline
\end{tabular}

$\star$ Between group differences for week 1 are significant at $\mathrm{p}=0.014$.

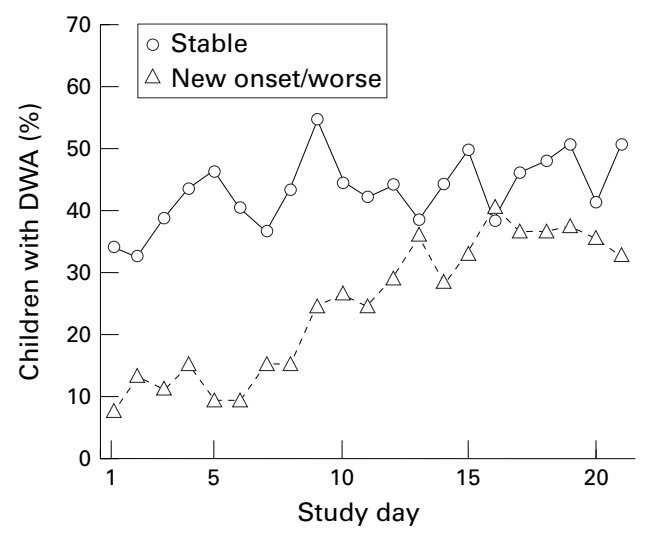

Figure 1 The percentage of children in the stable and new onset/worse groups with a day without asthma (DWA) for each study day. A day without asthma was defined as a day with no $\beta$ agonist use, no daytime asthma symptoms, no night-time awakenings, no unscheduled visits to a physician or emergency department or admission to a hospital for asthma, and no use of oral steroids for asthma.

interventional studies of children and adolescents with persistent asthma. The three daytime symptom questions, the awakening question, a combined daytime symptom scale score, and a day without asthma were validated in our study to determine their measurement characteristics.

The daytime symptom questions, combined daytime symptom scale, and day without asthma were found to have acceptable measurement characteristics in this population of children with asthma, aged 6-14 years, with persistent asthma symptoms. The daytime symptom questions, the combined daytime symptom scale, and the day without asthma outcome measure were able to: (1) discriminate between a stable group and a worse/new onset asthma group during study week 1 (baseline); (2) show moderate to good longitudinal construct validity with change in other measures of asthma evaluated in our study, except $\mathrm{FEV}_{1}$; and (3) show responsiveness to change in treatment from week 1 to week 3 in the worse/new onset group as compared with no change in treatment in the stable group.

The awakening question did not perform as well as the daytime questions, the combined daytime symptom scale, or day without asthma on any of the tests of validity or reliability. In addition, this question was not responsive to change in treatment in this group of children with asthma. However, we may not have been able to demonstrate acceptable discriminant validity and responsiveness for the awakening question because these children were not selected for presenting with nocturnal symptoms, as confirmed by the fact that fewer than half (48 of the 106 children (45\%)) had at least one awakening with asthma symptoms during the first week of the study. Although the discriminant validity and responsiveness of the awakening question were not found to be acceptable in our study, the assessment of awakenings is commonly included in trials of asthma treatments and it is an important indicator of increasing asthma severity. ${ }^{26}$ If it is desired to study the effect of treatment on night-time awakenings, it would be important 
to select a population based on frequent nighttime awakenings on their current treatment, or on placebo during a run in period.

The scores for the three daytime questions and the awakening question were not normally distributed in our study population. The mean scores for the scales were all $<1$ on a scale of $0-5$ for the daytime questions and $0-3$ for the awakening question for both the stable and new onset/worse groups. This indicates that most of the children in both asthma groups reported either no symptoms/limitations or very mild symptoms/limitations during the three week period. The level of symptom burden in this population of children with asthma appears to be consistent with the literature, which reports that children and adolescents generally tend to minimise their report of asthma symptoms and limitations compared with adults. ${ }^{27}$

Because of the non-normal distribution of the data, we used non-parametric methods for analysis for each of the daily diary questions and the total score. These methods are conservative and do not rely on an assumption of normally distributed responses. We recognise that other methods of analysis using average symptom scores may be appropriate. ${ }^{26} \mathrm{~A}$ small simulation study was conducted, which showed that the two analytical methods provide very consistent results and that both methods are applicable for analysis of these data.

The diary record also included measurement of twice daily PEF to assess pulmonary function. Although most clinical trials include periodic measurement of $\mathrm{FEV}_{1}$ to assess pulmonary function, daily or twice daily PEF provides an evaluation of the variability of asthma. The children and adolescents also recorded the number of puffs of $\beta$ agonist inhaler used during the day and at night. Both changes in daily PEF and changes in daily puffs of $\beta$ agonist inhaler used were found to correlate significantly with changes in the daytime symptom questions and changes in the awakening question. The sizes of the correlation coefficients are acceptable because the symptom scores measure patient perception of their asthma rather than lung function or need for additional medication. Perception of symptoms is a clinically relevant outcome measure and is the measure that most physicians would use when determining response to treatment. Consistent with other research in children and adults, ${ }^{18}{ }^{28-31}$ changes in periodic measurement of $\mathrm{FEV}_{1}$ were not found to correlate significantly with changes in the asthma symptom questions.

We created a composite summary to determine the percentage of days without any report of asthma symptoms, $\beta$ agonist inhaler use, health care provider contacts, or oral corticosteroid use (day without asthma) for each group. There was a significant difference between the new onset/worse group, who received a change in asthma treatment, and the stable group, who did not receive a change in treatment, over the three week study for the percentage of days without asthma. This end point is similar to others that have been used in the literature for a symptom free day, ${ }^{32}$ and may be particularly useful to examine the response to a treatment.

Positive responses to questions on school loss and need for urgent care of asthma or use of oral corticosteroids occurred more frequently in the first study week in the new onset/worse group of children with asthma. With treatment, the days of school loss and need for urgent care or oral corticosteroids for the new onset/worse group decreased to a rate similar to that seen in the stable group. These questions should be included in an outcome measure of asthma in children and adolescents, because they provide an indicator of asthma control or severity and appear to be responsive to treatment.

O'Connor and Weiss have called for an evaluation of the validity, reliability, and responsiveness to treatment of asthma symptoms as outcome measures. ${ }^{1}$ We found that existing diary scales for assessing asthma symptoms have either not been rigorously validated, or if validated, data on their measurement characteristics were not provided or referenced. ${ }^{13-15 \text { 28-30 } 3233}$ We developed and evaluated the measurement characteristics of a daytime asthma symptom scale and an awakening with asthma question administered in a daily paediatric diary. The results indicate that the symptom scale and day without asthma outcome measure could detect an improvement in asthma symptoms in those patients where a change in asthma treatment was indicated. In addition, the diary scale and day without asthma measure could differentiate changes in the unstable asthma group from those in the stable asthma group. These data suggest that these measures would be a valuable outcomes of treatment intervention for persistent asthma in children.

The symptom scale questions would be most appropriate for use in children who demonstrate some level of symptom burden, to allow room for improvement in the scores. The use of these measures in clinical practice for follow up of the clinical care of an individual child or adolescent is not known from our validation study. As should be done with all scales, we are presently collecting additional data on the performance of the diary scales as outcome measures in other paediatric populations treated with other asthma treatments.

We gratefully acknowledge the participation of the following clinical sites and investigators in this outcome measure validation study: Allergy Associates Inc, New England Research Center, North Dartmouth, MA, USA (P Chervinsky, B M Goldstein, J H Noyes, S D Miller, and K H Munemasa); Clinical Trials of Orange County, CA, USA (S P Galant, C I Lin, and W G Harris); Allergy Associates, PC Research, Portland, OR, USA ( $M$ Noonan and J W Baker); Princeton Allergy and Asthma Associates, Princeton, NJ, USA (A Pedinoff, D L Southern, and J Caucine); Allergy Associates Medical Group, San Diego, CA, USA (B M Prenner); Allergy and Asthma Prevention and Treatment Center, Clinical Research Institute Inc. San Diego, CA, USA (J Seltzer, G A Cohen, and D Bortz); Department of Allergy Park Nicollet Medical Center, Minneapolis, MN, USA (R J Sveum, D F Graft, J S Kelloway, R J Morris, W F Schoenwetter, and R A Wyatt); Atlanta Allergy and
Immunology Research Foundation, Atlanta, GA, USA (D G Tinkelman, H J Silk, L D Guydon, and S Carroll). Funding for Tinkelman, H J Silk, L D Guydon, and S Carroll). Funding for
this study was provided by Merck Research Laboratories, Merck this study was
and Co. Inc.

The Pediatric Asthma Diary is available on request from Dr N C Santanello, Merck \& Co Inc. 


\section{Appendix}

Pediatric Asthma Diary (Copyright 1995 Merck \& Co, Inc)

\begin{tabular}{|c|c|c|c|c|c|c|}
\hline \multicolumn{7}{|l|}{ Daytime symptom score } \\
\hline $\begin{array}{l}\text { How much of the time did you have } \\
\text { trouble breathing today? }\end{array}$ & $\begin{array}{l}\text { None of } \\
\text { the time }\end{array}$ & $\begin{array}{l}\text { A little of } \\
\text { the time }\end{array}$ & $\begin{array}{l}\text { Some of the } \\
\text { time }\end{array}$ & $\begin{array}{l}\text { A good bit of } \\
\text { the time }\end{array}$ & $\begin{array}{l}\text { Most of the } \\
\text { time }\end{array}$ & All of the time \\
\hline Circle one number & 0 & 1 & 2 & 3 & 4 & 5 \\
\hline $\begin{array}{l}\text { How much did your asthma bother } \\
\text { you today? }\end{array}$ & $\begin{array}{l}\text { Did not } \\
\text { bother me }\end{array}$ & $\begin{array}{l}\text { Bothered } \\
\text { me a little }\end{array}$ & $\begin{array}{l}\text { Bothered me } \\
\text { somewhat }\end{array}$ & $\begin{array}{l}\text { Bothered me } \\
\text { a good deal }\end{array}$ & $\begin{array}{l}\text { Bothered me } \\
\text { very much }\end{array}$ & $\begin{array}{l}\text { Bothered me as } \\
\text { much as possible }\end{array}$ \\
\hline Circle one number & 0 & 1 & 2 & 3 & 4 & 5 \\
\hline $\begin{array}{l}\text { How much of the time did your asthma } \\
\text { limit your activity today? (activities } \\
\text { include any sort of physical activity: } \\
\text { running, playing, jumping, sports, } \\
\text { bike-riding, gym, etc.) }\end{array}$ & $\begin{array}{l}\text { None of } \\
\text { the time }\end{array}$ & $\begin{array}{l}\text { A little of } \\
\text { the time }\end{array}$ & $\begin{array}{l}\text { Some of the } \\
\text { time }\end{array}$ & $\begin{array}{l}\text { A good bit of } \\
\text { the time }\end{array}$ & $\begin{array}{l}\text { Most of the } \\
\text { time }\end{array}$ & All of the time \\
\hline Circle one number & 0 & 1 & 2 & 3 & 4 & 5 \\
\hline \multicolumn{7}{|l|}{ Night time awakening question } \\
\hline $\begin{array}{l}\text { Were you woken by asthma? (either } \\
\text { during the night or in the morning) }\end{array}$ & No & Once & $\begin{array}{l}\text { More than } \\
\text { once }\end{array}$ & $\begin{array}{l}\text { Awake all } \\
\text { night }\end{array}$ & & \\
\hline Circle one number & 0 & 1 & 2 & 3 & & \\
\hline
\end{tabular}

1 O'Connor GT, Weiss ST Clinical and symptoms measures. Am f Respir Crit Care Med 1994;149:S21-8.

2 Fitzpatrick R, Fletcher A, Gore S, Jones D, Spiegelhalter D, Cox D. Quality of life measures in health care. I. Application and issues in assessment. BMf 1992;305: 1074-7.

3 Fletcher A, Gore S, Jones D, Fitzpatrick R, Spiegelhalter D, Cox D. Quality of life measure in health care. II. Design, analysis and interpretation. BMF 1992;305:1145-8.

4 Rothman ML, Revicki DA. Issues in the measurement of health status in asthma research. Med Care 1993;31:M58296.

5 Juniper EF, Guyatt GH, Feeny DH, Ferrie PJ, Griffith LE, Townsend $M$. Measuring quality of life in children with asthma. Qual Life Res 1996;5:35-46.

6 Taylor GH, Rea HH, McNaughton, et al. A tool for measuring the asthma self-management competency of families. $\mathcal{F}$ Psychosom Res 1991;35:483-91.

7 Schlosser M, Havermans G. A self-efficacy scale for children and adolescents with asthma: construction and validation. F Asthma 1992;29:99-108.

8 Christie MJ, French D, Sowden A, West A. Development of child-centered disease-specific questionnaires for living with asthma. Psychosom Med 1993;55:5541-48.

9 French DJ, Christie MJ, Sowden AJ. The reproducibility of the childhood asthma questionnaires: measures of quality of life for children with asthma aged 4-16 years. Qual Life Res 1994;3:215-24.

10 Fritz GK, Overholser JC. Patterns of response to childhood asthma. Psychosom Med 1989;51:347-55.

11 Brunekreef B, Groot B, Rijcken B, Hoek G, Steenbekkers A, de Boer A. Reproducibility of childhood respiratory symp. Eur Respir 7 1992:5:930-5.

12 Usherwood TP, Scrimgeour A, Barber JH. Questionnaire to measure perceived symptoms and disability in asthma. Arch Dis Child 1990;65:779-81.

13 Childhood asthma management program (CAMP) forms Springfield, Virginia: US Department of Commerce. National Technical Information Service. PB95-137204, September 1994

14 Fish L, Wilson S, Starr-Schneidkraut N, Loes L, Page A. An asthma education program for parents of children under seven, using videotechnology. F Allergy Clin Immunol 1992; 89:188.

15 Connolly N, Godfrey S. Assessment of the child with asthma. 7 Asthma Res 1970;8:31-6.

16 Wilson NM, Silverman M. Treatment of acute, episodic asthma in preschool children using intermittent high dose asthma in preschool children using intermittent high dose
inhaled steroids at home. Arch Dis Child 1990;65:40710 .

17 Meltzer EO, Orgal HA, Ellis EF, Elgan HN, Hemstreet PB. Long-term comparison of three combinations of albuterol, theophylline, and beclomethasone in children with chronic asthma. F Allergy Clin Immunol 1992;90:2-11.
18 Santanello NC, Barber BL, Reiss TF, Friedman BS, Juniper EF, Zhang J. Measurement characteristics of two asthma symptom diary scales for use in clinical trials. Eur Respir $f$ 1997;10:646-51.

19 Lessler JT. Choosing questions that people can understand. Med Care 1995;33 (suppl 4): AS203-8.

20 Forsyth BH, Lessler JT. Cognitive laboratory methods: a taxonomy. In: Biemer PN, Groves RM, Lybert LE, Mathiowetz NA, Sudman S, eds. Measurement errors in surveys. New York: John Wiley and Sons, 1991:393-418.

21 Deyo RA, Diehr P, Patrick D. Reproducibility and health status measures. Statistics and strategies for evaluation. Control Clin Trials 1991;12:142S-58S.

22 Streiner DL, Norman GR. Health measurement scales: a practical guide to their development and use. Oxford: Oxford University Press, 1989

23 Cronbach LJ. Coefficient alpha and internal structure of test. Psychometrika 1951;16:197-234.

24 Nunnally JC. Psychometric theory, 2nd ed. New York: McGraw-Hill, 1978.

25 Tandon PK. Applications of global statistics in analyzing quality of life data. Stat Med 1990;9:819-27.

26 Cox DR, Fitzpatrick R, Fletcher AE, Gore SM, Spiegelhalter DJ, Jones DR. Quality of life assessment: can we keep it simple? Fournal of the Royal Statistical Society Series A 1992;155:353-93.

27 Ellis EF. Asthma in childhood. F Allergy Clin Immunol 1983; 72:526-39.

28 Malo JL, L'Archeveque J, Trudeau C, d'Aquino C, Cartier A. Should we monitor peak expiratory flow rates or record symptoms with a simple diary in the management of asthma? F Allergy Clin Immunol 1993;91:702-9.

29 Malo JL, Cartier A, Merland N, et al. Four-times-a-day dosing frequency is better than a twice-a-day regimen in subing frequency is better than a twice-a-day regimen in sub-
jects requiring a high-dose inhaled steroid budesonide, to jects requiring a high-dose inhaled steroid budesonide, to
control moderate to severe asthma. Am Rev Respir Dis control moderate

30 Van Essen-Zandvliet EE, Hughes MD, Waalkens HJ, Duiverman EJ. Effects of 22 months of treatment with inhaled corticosteroids and/or beta-2-agonists on lung function, airway, responsiveness, and symptoms in children with asthma. Am Rev Respir Dis 1992;146:547-54.

$31 \mathrm{McFadden}$ ER. Clinical physiologic correlates in asthma. $\mathcal{f}$ Allergy Clin Immunol 1986;77:1-5.

32 Rutten-van Mölken MPMH, Van Doorslaer EKA, Jansen MCC, Van Essen-Zandvliet EE, Rutten FFH. Cost effectiveness of inhaled corticosteroid plus bronchodilator therapy versus bronchodilator monotherapy in children therapy versus bronchodilator monotherapy in

33 Connett GJ, Lenney W, McConchie SM. The cost effectiveness of budesonide in severe asthmatics aged one to threeyears. British fournal of Medical Economics 1993;6: $127-34$. 